\title{
Sound Absorption Coefficient and Sound Transmission Loss of Rice Hull Mat ${ }^{1}$
}

\author{
Chun-Won $\mathrm{Kang}^{2} \cdot$ Nam-Ho Lee $\mathbb{B}^{3, \dagger} \cdot$ Sang-Sik Jang ${ }^{4} \cdot$ Ho-Yang Kang ${ }^{4}$
}

\begin{abstract}
The sound absorption coefficient and transmission loss of several types of rice hull mats with varying apparent densities and thicknesses are estimated in this paper using the transfer function and matrix methods, respectively, to evaluate the possibility of using rice hull as an acoustic construction material. The mean sound absorption rates of 10 -cm-thick rice hull mats with target densities of $0.10 \mathrm{~g} / \mathrm{cm}^{3}, 0.12 \mathrm{~g} / \mathrm{cm}^{3}$, and $0.14 \mathrm{~g} / \mathrm{cm}^{3}$ were $0.91,0.92$, and 0.95 , respectively, while those of the 1 -cm-thick plywood attached to the back of the rice hulls were $0.90,0.92$, and 0.92 , respectively. The means of the sound transmission loss of the $10 \mathrm{~cm}$-thick rice hull mats with the target densities of $0.10 \mathrm{~g} / \mathrm{cm}^{3}, 0.12 \mathrm{~g} / \mathrm{cm}^{3}$, and $0.14 \mathrm{~g} / \mathrm{cm}^{3}$ were $7.66 \mathrm{~dB}, 10.49 \mathrm{~dB}$, and $14.14 \mathrm{~dB}$, respectively, while those of the $1 \mathrm{~cm}$-thick plywood attached to the back of the rice hulls were $33.34 \mathrm{~dB}, 36.72 \mathrm{~dB}$, and $38.95 \mathrm{~dB}$, respectively. In conclusion, a rice hull mat could be used as acoustic construction materials because of its high sound absorption coefficient and sound transmission loss.
\end{abstract}

Keywords: rice hull, plywood, sound absorption coefficient, sound transmission loss, transfer function method, transfer matrix method

\section{INTRODUCTION}

Recently, as the interest in improving the quality of life has heightened, demand for control of the noise in residential environment has significantly increased because environmental noise was becoming more serious problem. (Kim et al., 2012; Kim, 2007; Kook et al., 2007; Lee et al., 2011; Hwang et al., 2013) Accordingly, the number of studies on the building materials with excellent sound absorption performance and on measurement of sound absorption has been increasing. (Jang et al., 2018; Kang et al., 2018a; Kang et al., 2019; Kang et al., 2011; Kang et al., 2018c) In addition, worldwide interest in recycling byproducts has been increasing because demand and supply instability of industrial resources and demand of greenhouse gas reduction as climate changing. Especially for Korea, due to the lack of natural resources, effective

${ }^{1}$ Date Received February 8, 2019, Date Accepted May 2, 2019

${ }^{2}$ Department of Housing Environmental Design, and Research Institute of Human Ecology, College of Human Ecology, Chonbuk National University, Jeonju 54896, Republic of Korea

${ }^{3}$ Department of Wood Science \& Technology, College of Agriculture \& Life Sciences, Chonbuk National University, Jeonju 54896, Republic of Korea

${ }^{4}$ Department of Forest Products, College of Agriculture \& Life Sciences, Chungnam National University, Daejeon 34134, Republic of Korea

† Corresponding author: Nam-Ho Lee (e-mail: enamho@jbnu.ac.kr, ORCID: 0000-0002-3124-7044) 
reuse technology of various industrial by-products is needed in order to save as much as resources.

The mechanism of sound absorption is to deplete or reduce the energy of sound, resulting in reducing reverberation and controlling reverberation time. Sound absorption materials should have high acoustic absorptivity and also have no or less a harmful effect on humans. The insulation of sound could be presented by the sound transmission loss computed from the ratio of transmitted sound energy vs. incident sound energy. The sound transmission loss could be measured by both of transfer matrix method and reverberation room method. The transfer matrix method using an impedance tube has the advantage of quick measurement over wide frequency range. The reverberation room method has the advantage of accurate measurement, but needs large spaces and specimens.

About 80 million tons of rice hulls are produced each year in Korea and most of them are consumed for low value-added livestock facilities. In this study, to evaluate the possibility of using rice hull mats as acoustic construction materials, sound absorption coefficient and sound transmission loss of various target densities and thicknesses of rice hull mats were measured by using transfer function method and transfer matrix method. They were compared with those values of the samples plywood attached to their back sides. Feasibility of applying the samples to interior building material was examined.

\section{MATERIALS and METHODS}

\subsection{Rice hull filling}

The apparent density of rice hull mats was reached through regulation of pressing pressure of a knob on the back side of sample holder after weighed amount of rice hulls were put into an impedance tube. A circular net was installed in front of the holder to prevent to rice hulls flow down by the gravity of rice hulls as shown in Fig. 2.

\subsection{Measuring sound absorption rate by transfer function method}

The sound absorption rate in practical frequency range was measured by transfer function method (ISO 10534-2) using impedance tube, pulse analysis software and a spectrum analyzer (B\&K Company) as precious research (Kang et al., 2012). In this study, the variation of sound absorption rate was measured as change of frequency in the range of $100 \mathrm{~Hz} \sim 6400 \mathrm{~Hz}$ using the impedance tube with the diameter of $29 \mathrm{~mm}$. During measurement, temperature, relative humidity and atmospheric pressure were $26.4{ }^{\circ} \mathrm{C}$, 68 percent and 1027.00 $\mathrm{hPa}$, respectively. The velocity of sound, air density and acoustic impedance were $346.98 \mathrm{~m} / \mathrm{s}, 1.192 \mathrm{~kg} / \mathrm{m}^{3}$ and $413.7 \mathrm{~Pa} /(\mathrm{m} / \mathrm{s})$, respectively.

\subsection{Measuring acoustic transmission loss by transfer matrix method}

The sound transmission coefficient, $\tau$, of a material is defined as the ratio of sound power transmitted per incident sound power expressed as follows,

$$
\tau=\mathrm{Wt} / \mathrm{Wi}
$$

Where

Wi is incident sound power

Wt is transmitted sound power

The sound transmission loss, STL, of a material is measured in decibels expressed as follows,

$$
\mathrm{STL}=10 \log 10(1 / \tau) \mathrm{dB}
$$

The sound transmission loss of specimens was measured by transfer matrix method (ASTM E2611 09) using impedance tube for estimating transmission loss (Fig. 1, B\&K Company), pulse analysis software 


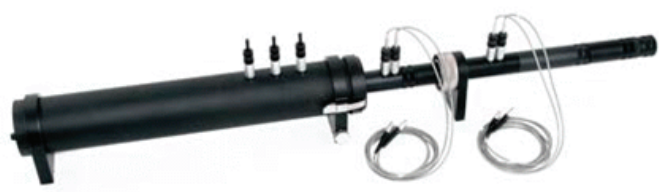

Fig. 1. Impedance tube for measuring sound transmission loss ratio (kang et al., 2018b).
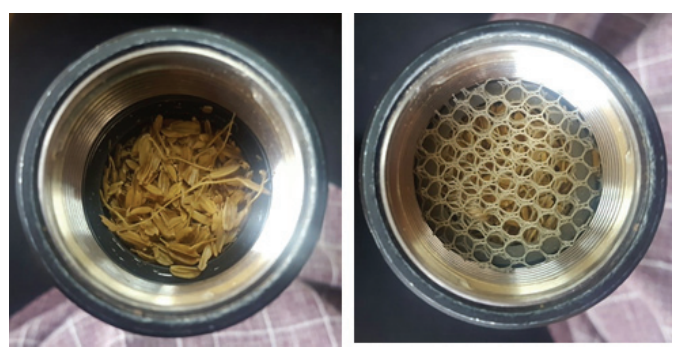

Fig. 2. Sample preparation for measuring sound absorption ratio and sound transmission loss.

and a spectrum analyzer (B\&K company) as precious research (Kang et al., 2018b). The estimation frequency range was $100 \sim 6400 \mathrm{~Hz}$. During measurement, temperature and atmospheric pressure were $24.4{ }^{\circ} \mathrm{C}$ and 1027.5 hPa, respectively.

\section{RESULTS and DISCUSSION}

\subsection{Sound absorption rate by transfer function method}

As shown in Fig. 3, the sound absorption rates of rice hull mat with apparent density of 0.10 measured by transfer function method showed in the range of $100 \mathrm{~Hz} \sim 6400 \mathrm{~Hz}$. As the thickness of specimens increased from $20 \mathrm{~mm}$ to $30 \mathrm{~mm}, 50 \mathrm{~mm}, 80 \mathrm{~mm}$ and $100 \mathrm{~mm}$, average sound absorption rates was $0.53,0.67$, 0.76, 0.87 and 0.91 , which indicates that average sound absorption rate increases as the thickness of specimens increasing. The frequency at which, sound absorption rate significantly increased, first peak occurred was 2912, 2120, 1200, 760 and $584 \mathrm{~Hz}$, at this time sound absorption rate was $0.80,0.82,0.84,0.95$ and 0.96 .

As shown in Fig. 4, the sound absorption rates of rice hull mat with apparent density of 0.12 measured by transfer function method showed in the range of $100 \mathrm{~Hz} \sim 6400 \mathrm{~Hz}$. As the thickness of specimens increased from $20 \mathrm{~mm}$ to $30 \mathrm{~mm}, 50 \mathrm{~mm}, 80 \mathrm{~mm}$ and $100 \mathrm{~mm}$, average sound absorption rates was $0.61,0.67$, 0.83, 0.89 and 0.92 , which indicates that average sound

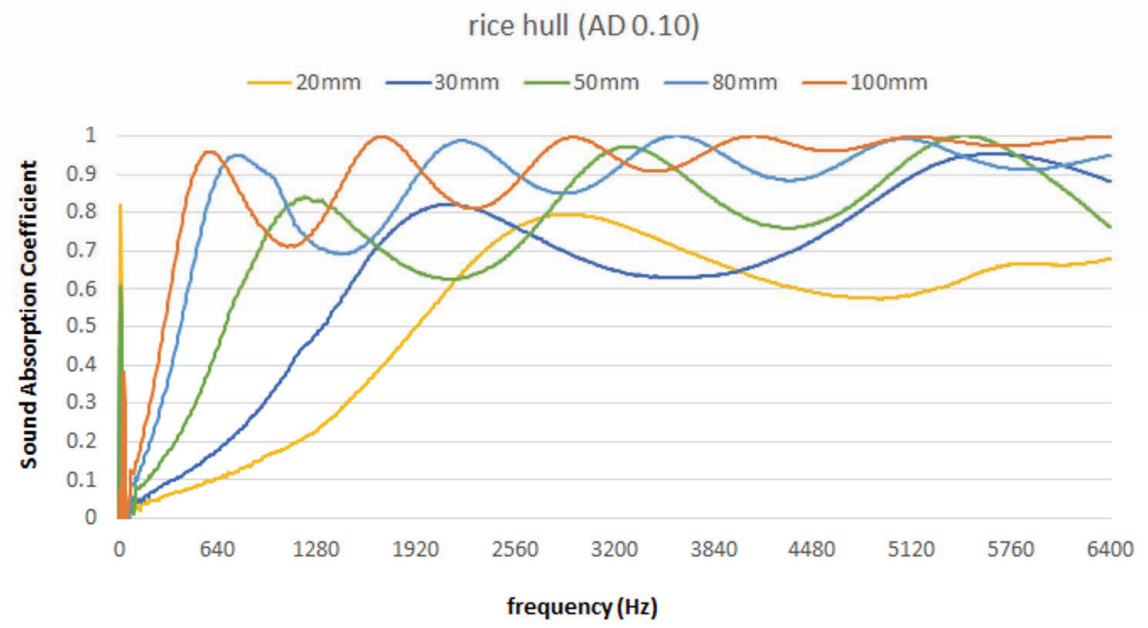

Fig. 3. Sound absorption rate of rice hull mat with apparent density of 0.10 (Graph legend values denote sample thickness). 


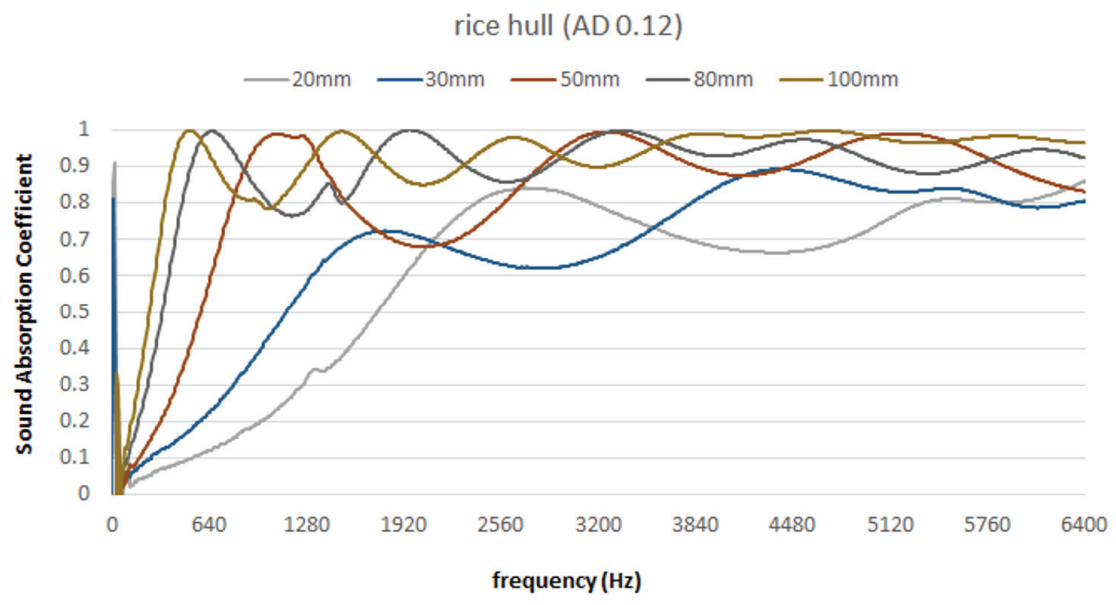

Fig. 4. Sound absorption rate of rice hull mat with apparent density of 0.12 (Graph legend values denote sample thickness).

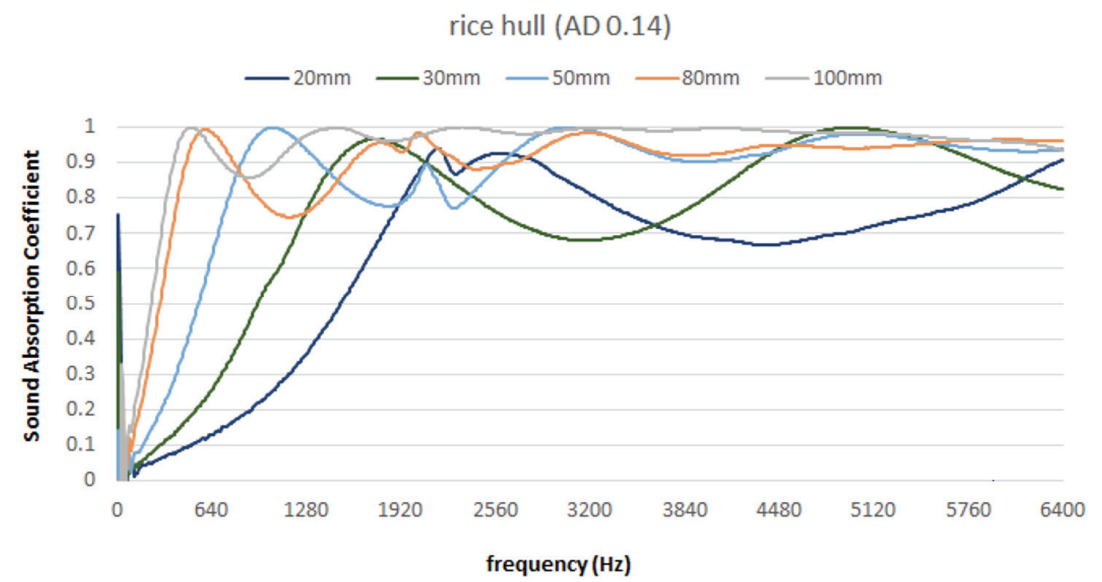

Fig. 5. Sound absorption rate of rice hull mat with apparent density of 0.14 (Graph legend values denote sample thickness).

absorption rate increases as the thickness of specimens increasing. The frequency at which, sound absorption rate significantly increased, first peak occurred was 2720, 1792, 1080, 664 and $504 \mathrm{~Hz}$, at this time sound absorption rate was $0.84,0.72,0.99,0.997$ and 0.999 .

As shown in Fig. 5, the sound absorption rates of rice hull mat with apparent density of 0.14 were measured by transfer function method in the range of $100 \mathrm{~Hz} \sim 6400 \mathrm{~Hz}$. As the thickness of specimens increased from $20 \mathrm{~mm}$ to $30 \mathrm{~mm}, 50 \mathrm{~mm}, 80 \mathrm{~mm}$ and $100 \mathrm{~mm}$, average sound absorption rates was $0.64,0.76$, 0.86, 0.90 and 0.95 . It could be concluded that average sound absorption rate increases with the thickness of specimens. When sound absorption rates significantly increased, the frequencies at the first peaks were 2160, 1744, 1048, 592 and $496 \mathrm{~Hz}$, and their corresponding sound absorption rates were $0.94,0.97,0.999,0.994$ and 0.999 . 


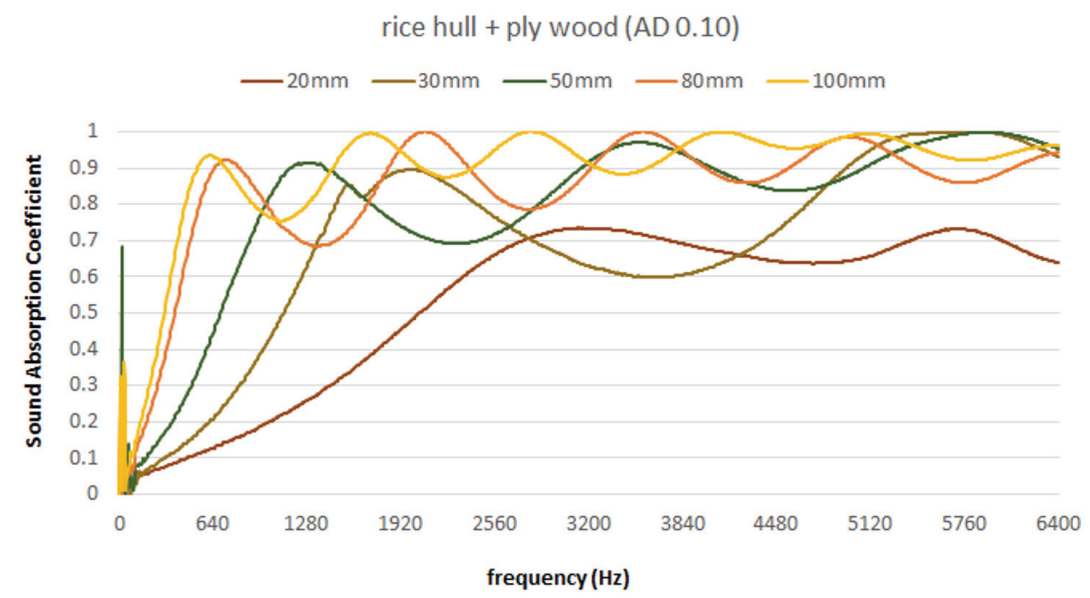

Fig. 6. Sound absorption rate of $1 \mathrm{~cm}$ thick plywood attached rice hull mat with apparent density of 0.10 (Graph legend values denote sample thickness).

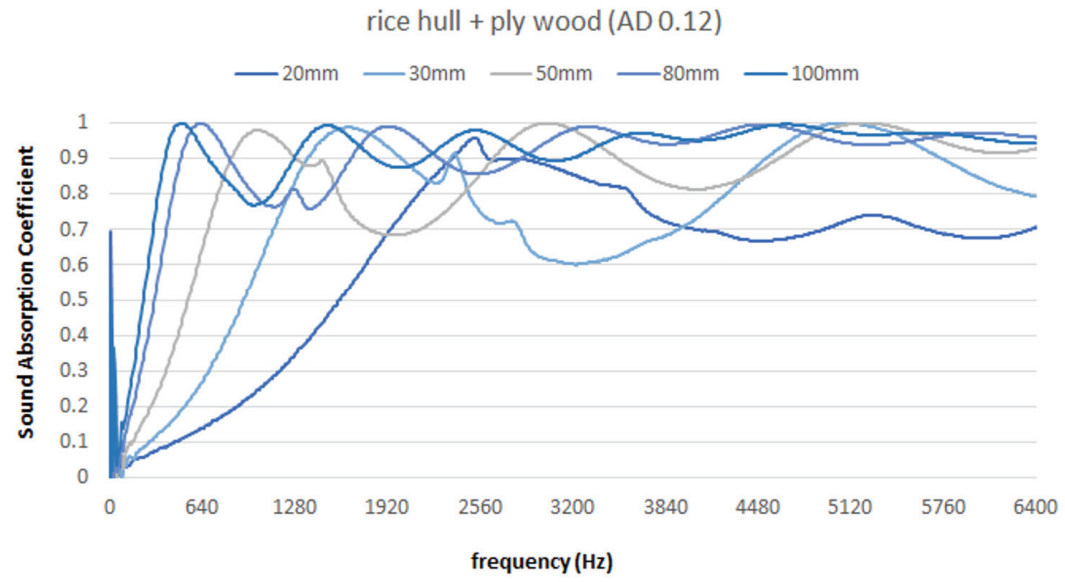

Fig. 7. Sound absorption rate of $1 \mathrm{~cm}$ thick plywood attached rice hull mat with apparent density of 0.12 (Graph legend values denote sample thickness).

As shown in Fig. 6, the sound absorption rates of the specimens which were $10 \mathrm{~mm}$ thick plywood attached the back of rice hull mat with apparent density of 0.10 measured by transfer function method are shown in the range of $100 \mathrm{~Hz} \sim 6400 \mathrm{~Hz}$. As the thickness of specimens increased from $20 \mathrm{~mm}$ to $30 \mathrm{~mm}, 50 \mathrm{~mm}$, $80 \mathrm{~mm}$ and $100 \mathrm{~mm}$, average sound absorption rates were $0.54,0.70,0.80,0.85$ and 0.90 , which indicates that average sound absorption rate increases as the thickness of specimens increases. The frequency at which, sound absorption rate significantly increased, first peak occurred was 3120, 2080, 1312, 712 and $624 \mathrm{~Hz}$, at this time sound absorption rate was $0.73,0.89,0.92$, 0.92 and 0.93 .

As shown in Fig. 7, the sound absorption rates of the specimens which were $10 \mathrm{~mm}$ thick plywood attached the back of rice hull mat with apparent density of 0.12 measured by transfer function method are shown 


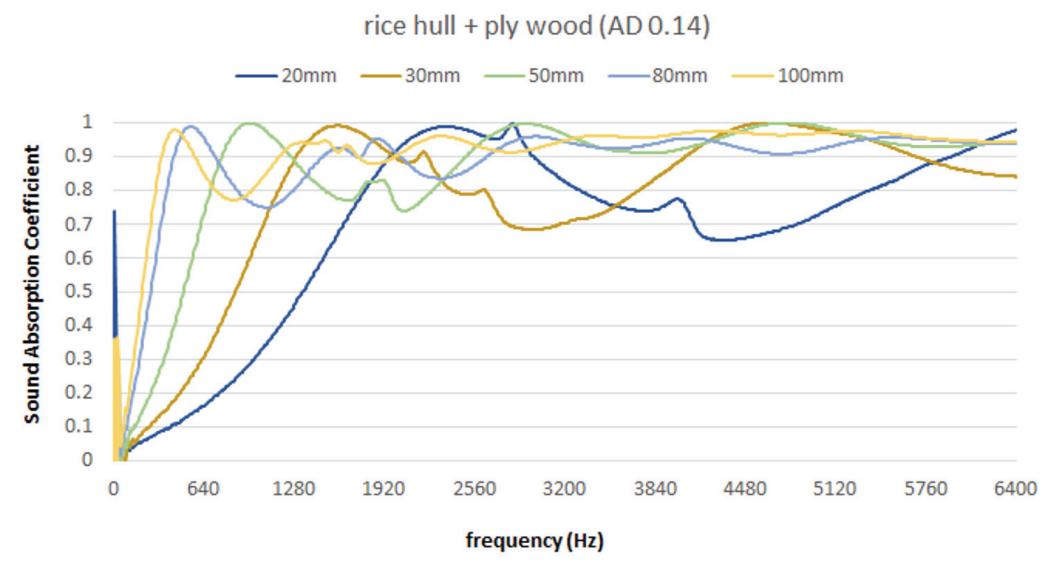

Fig. 8. Sound absorption rate of $1 \mathrm{~cm}$ thick plywood attached rice hull mat with apparent density of 0.14 (Graph legend values denote sample thickness).

in the range of $100 \mathrm{~Hz} \sim 6400 \mathrm{~Hz}$. As the thickness of specimens increased from $20 \mathrm{~mm}$ to $30 \mathrm{~mm}, 50 \mathrm{~mm}$, $80 \mathrm{~mm}$ and $100 \mathrm{~mm}$, average sound absorption rates was $0.62,0.74,0.84,0.90$ and 0.92 , which indicates that average sound absorption rate increases as the thickness of specimens increasing. The frequency at which, sound absorption rate significantly increased, first peak occurred was 2520,1548, 1024, 632 and $496 \mathrm{~Hz}$, at this time sound absorption rate was 0.96, 0.99, 0.98, 0.99 and 0.99 .

As shown in Fig. 8, the sound absorption rates of specimens which were $10 \mathrm{~mm}$ thick plywood attached the back of rice hull mat with apparent density of 0.14 measured by transfer function method are shown in the range of $100 \mathrm{~Hz} \sim 6400 \mathrm{~Hz}$. As the thickness of specimens increased from $20 \mathrm{~mm}$ to $30 \mathrm{~mm}, 50 \mathrm{~mm}$, $80 \mathrm{~mm}$ and $100 \mathrm{~mm}$, average sound absorption rates was $0.70,0.79,0.87,0.89$ and 0.92 , which indicates that average sound absorption rate increases as the thickness of specimens increases. The frequency at which, sound absorption rate significantly increased, first peak occurred was 2352, 1584, 968, 544 and $432 \mathrm{~Hz}$, at this time sound absorption rate was 0.99, 0.99, 0.999, 0.99 and 0.98 .
As a whole, average sound absorption rate of rice hull mats presents an increasing trend as the thickness of specimens increases and the frequency at which first peak occurred decreases while sound absorption rate increases as the thickness of specimen increases. The average sound absorption rate was $0.54-0.92$ for $10 \mathrm{~mm}$ thick plywood attached the back of rice hull mats and 0.53 - 0.95 for rice hull mats, which was $1 \%$ lower than that for rice hull mats. Especially, The average sound absorption rate was 0.93 for $10 \mathrm{~mm}$ thick plywood attached the back of rice hull mats and 0.95 for rice hull mats when the thickness of specimens was $100 \mathrm{~mm}$ in the range of $100 \mathrm{~Hz} \sim 6400 \mathrm{~Hz}$. On the other hand, the noise reduction coefficient of the gypsum board usually used for ceiling in office or classroom presented about 0.30 while that value of $10 \mathrm{~cm}$ thick rice hull mat with the density of $0.14 \mathrm{~g} / \mathrm{cm}^{3}$ in this study presented about 0,35 , which was better than the former.

\subsection{Sound transmission loss measured by transfer matrix method}

The acoustic transmission loss of rice hulls and rice hull mats is shown in Fig. 9 when the densities were $0.1,0.12$ and 0.14 , and the thickness of specimens was 


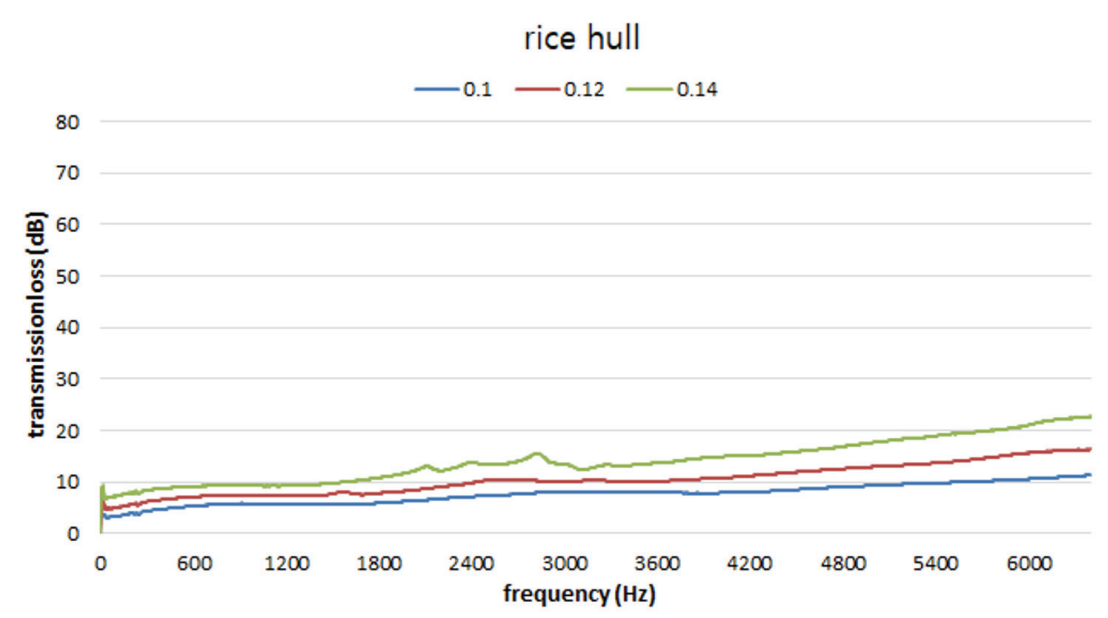

Fig. 9. Sound transmission loss of $10 \mathrm{~cm}$ thick rice hull mat (Graph legend values denote apparent density of rice hull mat).

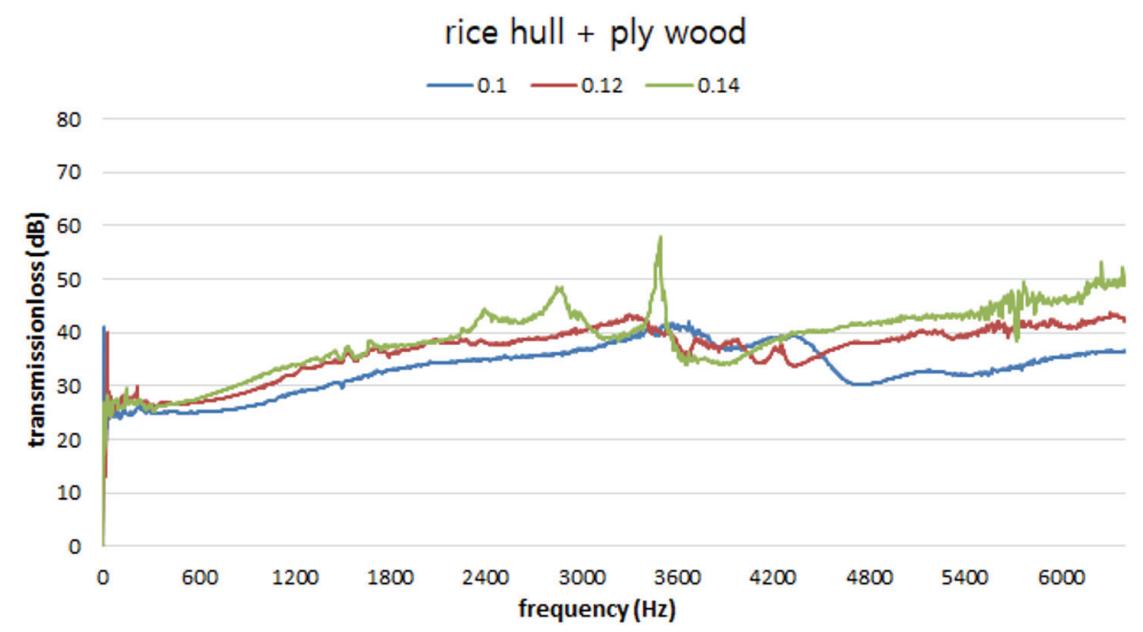

Fig. 10. Sound transmission loss of $1 \mathrm{~cm}$ thick plywood attached $10 \mathrm{~cm}$ thick rice hull mat (Graph legend values denote apparent density of rice hull mat).

$100 \mathrm{~mm}$. When the density was 0.1 , the acoustic transmission loss was $4.26 \mathrm{~dB}$ between the frequency range of $100 \mathrm{~Hz} \sim 500 \mathrm{~Hz}, 5.56 \mathrm{~dB}$ between the frequency range of $500 \mathrm{~Hz} \sim 1000 \mathrm{~Hz}$ and $8.11 \mathrm{~dB}$ between the frequency range of $1000 \mathrm{~Hz} \sim 6400 \mathrm{~Hz}$. Their average value was $7.66 \mathrm{~dB}$. When the density was 0.12 , the acoustic transmission loss was $6.06 \mathrm{~dB}$ between the frequency range of $100 \mathrm{~Hz} \sim 500 \mathrm{~Hz}, 7.28$ $\mathrm{dB}$ between the frequency range of $500 \mathrm{~Hz} \sim 1000 \mathrm{~Hz}$ and $11.12 \mathrm{~dB}$ between the frequency range of 1000 $\mathrm{Hz} \sim 6400 \mathrm{~Hz}$, average value being $10.49 \mathrm{~dB}$. When the density was 0.14 , the acoustic transmission loss was $8.24 \mathrm{~dB}$ between the frequency range of $100 \mathrm{~Hz}$ $500 \mathrm{~Hz}, 9.23 \mathrm{~dB}$ between the frequency range of 500 $\mathrm{Hz} \sim 1000 \mathrm{~Hz}$ and $15.03 \mathrm{~dB}$ between the frequency range of $1000 \mathrm{~Hz} \sim 6400 \mathrm{~Hz}$, average value being $14.14 \mathrm{~dB}$. Although sound insulation performance of rice hull mats was low because sound pass through among the 
particles, the sound insulation performance increased by 1.85 times $(6.48 \mathrm{~dB})$ as the density increased from 0.1 to 0.14 .

The sound transmission loss of $10 \mathrm{~mm}$ thick plywood attached the back of rice hulls is shown in Fig. 9. The sound transmission loss was significantly increased because the sound transmission loss was proportional to the surface density of the specimens.

The sound transmission loss was $25.08 \mathrm{~dB}$ between the frequency range of $100 \mathrm{~Hz} \sim 500 \mathrm{~Hz}, 25.55 \mathrm{~dB}$ between the frequency range of $500 \mathrm{~Hz} 1000 \mathrm{~Hz}$ and $34.67 \mathrm{~dB}$ between the frequency range of $1000 \mathrm{~Hz} \sim$ $6400 \mathrm{~Hz}$, average value being $33.34 \mathrm{~dB}$, when the density was 0.1 . When the density was 0.12 , sound transmission loss was $26.99 \mathrm{~dB}$ between the frequency range of $100 \mathrm{~Hz} \sim 500 \mathrm{~Hz}, 27.86 \mathrm{~dB}$ between the frequency range of $500 \mathrm{~Hz} \sim 1000 \mathrm{~Hz}$ and $38.26 \mathrm{~dB}$ between the frequency range of $1000 \mathrm{~Hz} \sim 6400 \mathrm{~Hz}$. Their average value was $36.72 \mathrm{~dB}$. When the density was 0.14 , acoustic transmission loss was $26.55 \mathrm{~dB}$ between the frequency range of $100 \mathrm{~Hz} \sim 500 \mathrm{~Hz}$, 29.19dB between the frequency range of $500 \mathrm{~Hz} \sim 1000$ $\mathrm{Hz}$ and $40.77 \mathrm{~dB}$ between the frequency range of 1000 $\mathrm{Hz} \sim 6400 \mathrm{~Hz}$, average value being $38.95 \mathrm{~dB}$.

Although sound insulation performance of rice hull mats was low because sound pass through among the particles, the sound insulation performance increased by 1.17 times $(5.61 \mathrm{~dB})$ as the density increased from 0.1 to 0.14 .

The acoustic transmission loss of rice hulls generally presented lower value because the density of thin rice hulls was low in this study. The acoustic transmission loss showed an increasing trend as frequency increases, and presented low value, being $4-12 \mathrm{~dB}$, which was difficult to expect to have good acoustic isolation effect. However, acoustic transmission loss of rice hulls attached plywood increased, being $25-50 \mathrm{~dB}$.

\section{CONCLUSION}

The sound absorption coefficient and sound transmission loss of different apparent densities with 0.10 , 0.12 and 0.14 and thicknesses of $2 \mathrm{~cm}, 4 \mathrm{~cm}, 6 \mathrm{~cm}$, $8 \mathrm{~cm}$ and $10 \mathrm{~cm}$ rice hull mats were measured and compared to those values of $1 \mathrm{~cm}$ thick plywood attached rice hull mats, in this study.

1. The sound absorption coefficient of rice hull mats was increased with the target density and mat thickness. Its mean value of $10 \mathrm{~cm}$ thick rice hull mats with the target density of 0.14 was 0.99 , was higher than that of $1.1 \mathrm{~cm}$ thick commercial gypsum board. It was possible that rice hull mats was used as sound-absorbing materials. There are almost no difference between rice hull mats and plywood attached rice hull mats.

2. The sound transmission loss of rice hull mats were 4-9 dB while sound transmission loss of plywood attached rice hulls was $25-40 \mathrm{~dB}$.

3. The $1 \mathrm{~cm}$ thick plywood attached $10 \mathrm{~cm}$ thick rice hulls mats with the target density of 0.14 was expected to use as acoustic construction materials due to its highly sound absorbing and good acoustic isolation performance.

\section{ACKNOWLEDGMENT}

This research was supported by Basic Science Research Program through the National Research Foundation of Korea (NRF) funded by the Ministry of Science and ICT(NRF-2017R1A2B4012538)

\section{REFERENCES}

ASTM E2611 - 09 Standard Test Method for Measurement of Normal Incidence Sound Transmission of Acoustical Materials Based on the Transfer Matrix 
Method.

Hwang, S.-M., Kim, J.-D., Kwon, H., Seo, Y.-S. 2013. Sound Transmission Loss through Double Walls. International Journal of Naval Architecture and Ocean Engineering 50(2): 64-68.

ISO 10534-2, Acoustics-Determination of sound absorption coefficient and impedance in impedance tubes-Part 2 : Transfer function method.

Jang, E.-S., Kang, C.-W., Kang, H.-Y., Jang, S.-S. 2018. Sound Absorption Property of Traditional Korean Natural Wallpaper (Hanji). Journal of the Korean Wood Science and Technology 46(6): 703-712.

Kang, C.-W., Jang, E.-S., Jang, S.-S., Kang, H.-Y. 2018a. Comparison of Transfer Function Method and Reverberation Room Method in Measuring the Sound Absorption Coefficient of Rice Straw Particle Mat. Journal of the Korean Wood Science and Technology 46(4): 362-367.

Kang, C.-W., Jang, E.-S., Jang, S.-S., Kang, H.-Y. 2018b. Measurement of Sound Transmission Loss in a Sound Barrier Filled with the Rice-Straw Particles by the Transfer Function and Laboratory Measurement Methods. Journal of the Korean Wood Science and Technology 46(4): 338-345.

Kang, C.-W., Jang, E.-S., Jang, S.-S., Kang, H.-Y. 2018c. Changes in sound absorption capability and air permeability of Malas (homalium foetidum) specimens after high temperature heat treatment. Journal of the Korean Wood Science and Technology 46(2): 149-154.

Kang, C.-W., Jang, S.-S., Kang, H.-Y. Li, C. 2019. Sound Absorption Rate and Sound Transmission
Loss of CLT Wall Panels Composed of Larch Square Timber Core and Plywood Cross Band. Journal of the Korean Wood Science and Technology 47(1): 33-39.

Kang, C.-W., Lee, Y.-H., Kang, H.-Y., Kang, W., Xu, H.-R., Chung, W.-Y. 2011. Radial variation of sound absorption capability in the cross sectional surface of yellow poplar wood. Journal of the Korean Wood Science and Technology 39(4): 326-332.

Kang, C.-W., Oh, S.-W., Lee, T.-B., Kang, W., Matsumura, J. 2012. Sound absorption capability and mechanical properties of a composite rice hull and sawdust board. Journal of Wood Science 8: 273-278.

Kim, C.-W., Chang, T.-C., Kim, D.-S. 2012. Characteristics Analysis of Highway Traffic Noise. Transactions of the Korean Society of Noise and Vibration Engineering 22(12): 1191-1198.

Kim, J.-S. 2007. Characteristics of sound from construction equipment machinery room International Journal of Air-Conditioning and Refrigeration 36(1): 19-25.

Kook, J.-H., Jung, C.-W., Yun, J.-H., Kim, J.-S. 2007. Experimental Study on Wall Sound Transmission Loss at Construction Equipment Machinery Room. Transactions of the Korean Society of Noise and Vibration Engineering 3: 695-699.

Lee, J.-H., Kim, B.-S., Kim, K.-J. 2011. Study of Sound Transmission Characteristics of using a Scale Reverberation Chamber and vibro acoustic FEM. Transactions of the Korean Society of Noise and Vibration Engineering 10: 92-95. 